\title{
Study may not be the best approach to assessing link between QOF and premature death
}

\author{
Kate E Honeyford research associate, L S Levene general practice principal, Leicester, and honorary \\ clinical fellow, Richard Baker professor of quality in health care
}

Department of Health Sciences, University of Leicester, Leicester LE1 6TP, UK

Although Kontopantelis and colleagues found no association between recorded practice performance under the Quality and Outcomes Framework (QOF) and premature death rates, we are not convinced that improvements in healthcare, as measured through QOF, have no impact on population health. ${ }^{1}$

Our cross sectional studies of premature death from coronary heart disease in a sample of practices ${ }^{23}$ and two studies at primary care trust level of all age mortality ${ }^{45}$ for all England found that some clinical management variables explain variations in premature (under 75 years) and all age mortality. Furthermore, better detection of hypertension was associated with lower mortality from stroke and coronary heart disease-that is, the more patients on practice hypertension registers, the lower the mortality. This highlights the need to provide care for the whole practice population to improve population health.

We would also challenge whether the selection of QOF indicators and their aggregation was the most useful approach. Individual QOF indicators and combined scores related to the cause of death have been shown to be related to all age and premature mortality. ${ }^{2-6}$ However, the relevance of the combined indicators to the specific causes of disease considered in the paper is not clear. In addition, the consideration of QOF indicators that focus on hypertension management in specific disease groups rather than on the numbers of patients on hypertension registers ignores the important role of general practice in primary prevention. We also do not understand why they did not include a measure of smoking prevalence. ${ }^{3}$

Finally, we could not see a clear definition of premature mortality in the paper.

Competing interests: None declared.

Kontopantelis E, Springate DA, Ashworth M, et al. Investigating the relationship between quality of primary care and premature mortality in England: a spatial whole-population study. BMJ 2015;350:h904. (2 March.)

2 Honeyford K, Baker R, Bankart MJG, et al. Modelling factors in primary care quality improvement: a cross-sectional study of premature CHD mortality. BMJ Open 2013;3:e003391

3 Honeyford K, Baker R, Bankart MJG, et al. Estimating smoking prevalence in general practice using data from the Quality and Outcomes Framework (QOF). BMJ Open 2014;4:e005217.

4 Levene LS, Baker R, Bankart MJG, et al. Association of features of primary health care with coronary heart disease mortality. JAMA 2010;304:2028-34.

5 Levene LS, Bankart J, Khunti K, et al. Association of primary care characteristics with variations in mortality rates in England: an observational study. PLoS One 2012;7:e47800.

6 Kiran T, Hutchings A, Dhalla IA, et al. The association between cardiovascular outcomes: a cross-sectional study using data from the UK Quality and Outcomes Framework. J Epidemiol Community Health 2010;64:927-34.

Cite this as: BMJ 2015;350:h1675

(๑) BMJ Publishing Group Ltd 2015 